\title{
Review of the Management of Obstructive Sleep Apnea and Pharmacological Symptom Management
}

\author{
Ladan Panahi ${ }^{1,2, *(\mathbb{D})}$, George Udeani ${ }^{1,2, *(\mathbb{D})}$, Steven Ho ${ }^{1,2}$, Brett Knox ${ }^{1,2}$ and Jason Maille ${ }^{1,2}$ \\ 1 Department of Pharmacy Practice, Texas A\&M Rangel College of Pharmacy, 1010 W Ave B, \\ Kingsville, TX 78363, USA; stevencuong0902@tamu.edu (S.H.); bknox@tamu.edu (B.K.); \\ maille@tamu.edu (J.M.) \\ 2 Department of Pharmacy Practice, Texas A\&M Rangel College of Pharmacy, 59 Reynolds Medical Building, \\ College Station, TX 77843, USA \\ * Correspondence: Panahi@tamu.edu (L.P.); udeani@tamu.edu (G.U.)
}

check for updates

Citation: Panahi, L.; Udeani, G.; Ho, S.; Knox, B.; Maille, J. Review of the Management of Obstructive Sleep Apnea and Pharmacological Symptom Management. Medicina 2021, 57, 1173. https://doi.org/ 10.3390/medicina57111173

Academic Editor: Stuart F. Quan

Received: 29 September 2021

Accepted: 26 October 2021

Published: 28 October 2021

Publisher's Note: MDPI stays neutral with regard to jurisdictional claims in published maps and institutional affiliations.

Copyright: (C) 2021 by the authors. Licensee MDPI, Basel, Switzerland. This article is an open access article distributed under the terms and conditions of the Creative Commons Attribution (CC BY) license (https:// creativecommons.org/licenses/by/ $4.0 /)$.

\begin{abstract}
Nearly a billion adults around the world are affected by a disease that is characterized by upper airway collapse while sleeping called obstructive sleep apnea or OSA. The progression and lasting effects of untreated OSA include an increased risk of diabetes mellitus, hypertension, stroke, and heart failure. There is often a decrease in quality-of-life scores and an increased rate of mortality in these patients. The most common and effective treatments for OSA include continuous positive airway pressure (CPAP), surgical treatment, behavior modification, changes in lifestyle, and mandibular advancement devices. There are currently no pharmacological options approved for the standard treatment of OSA. There are, however, some pharmacological treatments for daytime sleepiness caused by OSA. Identifying and treating obstructive sleep apnea early is important to reduce the risks of future complications.
\end{abstract}

Keywords: obstructive sleep apnea (OSA); pharmacotherapy

\section{Introduction and Background}

Obstructive sleep apnea (OSA) is characterized by nighttime awakenings, hypoxia, and hypercapnia caused by the airway constricting partially or fully while sleeping [1] The signs of OSA include daytime drowsiness, narcolepsy, cognitive impairment, and snoring while sleeping. Because these symptoms can go overlooked due to a relative lack of urgency, OSA often goes untreated. This increases the risk of conditions such as atrial fibrillation, stroke, heart failure, myocardial infarction, hypertension, and pulmonary hypertension [2-6]. An estimated forty to sixty percent of patients with cardiovascular disease (CVD) have OSA [7]. Many OSA patients also have diabetes mellitus, hyperlipidemia, and hypertriglyceridemia [8]. Overstimulation of the sympathetic nervous system, metabolic dysfunction, endothelial dysfunction, and systemic inflammation are all possible pathophysiological mechanisms that may be responsible for the risks of OSA $[2,8]$.

\section{Pathophysiology}

\subsection{Sympathetic Nervous System}

Sleep is typically characterized by the dominance of parasympathetic activity in the body. Decreased oxygen and increased $\mathrm{CO}_{2}$ caused by an airway obstruction lead to increased sympathetic output in the periphery and central chemoreceptors $[8,9]$. Increased sympathetic output remains present during sleep and while awake. The study conducted by Narkiewicz et al. compared sympathetic responses among obese patients with or without OSA. The study showed that an increased sympathetic response was found in obese patients with OSA but was not found in the control obese group without OSA [9]. Because the obese patients without OSA did not have an increased sympathetic response, it is possible that OSA is the causative factor for having an increased sympathetic response [10]. 
The renin-angiotensin-aldosterone system (RAAS) is activated by the sympathetic neurons and, since the sympathetic response is found to be upregulated in patients with OSA, the RAAS system is also overstimulated. Patients with OSA often have elevated angiotensin II and aldosterone hormone levels in the body. Increases in these levels lead to water retention in the kidneys and vasoconstriction in the peripheral vasculature [11]. As a result of these mechanisms being activated, hypertension is commonly found in patients with OSA [12].

\subsection{Endothelial Dysfunction}

Endothelial cells normally release vasoactive and vasorelaxant factors to regulate the vascular tone. In OSA, the endothelial cells do not function in the same capacity [13]. Phillips et al., in a prospective study of OSA patients, measured oxygen saturation, hemodynamics, and changes in circulating endothelin-1 levels [14]. The study found that, after OSA treatment, patients experienced decreases in blood pressure and endothelin-1 [14,15]. Nitric oxide, which normally serves as a vasodilator, was found to have impaired action in OSA; however, the impaired action was reversible after CPAP treatment [16].

\subsection{Systemic Inflammation}

In OSA, there are increased inflammatory biomarkers such as interleukin-6 (IL-6) and tumor necrosis factor-alpha (TNF-a) [17-19]. This condition can be considered a lowgrade chronic inflammatory disease [17-19]. In addition to the inflammatory biomarkers, concentrations of reactive oxygen species are increased due to the hypoxia caused by the night-time intermittent airway obstruction [20]. Increased reactive oxygen species in addition to the inflammation biomarkers mentioned above indicate a possible mechanism by which OSA increases risk of cardiovascular disease and overall mortality.

\subsection{Metabolic Dysfunction}

Type 2 diabetes mellitus (T2DM) is more prevalent in OSA populations. This is notable because T2DM may increase all-cause mortality and the risk of CVD. In a crosssectional analysis of 2588 participants, the Sleep Heart Health Study found a link between obstructive sleep apnea and elevated fasting glucose, decreased glucose tolerance, and diabetes mellitus [21]. Nadeem at al. conducted a meta-regression analysis determining that there was increased LDL, triglycerides, and total cholesterol in patients with OSA [22]. This is notable because increases in these factors as well as blood glucose are risk factors for cardiovascular disease.

\section{Epidemiology}

Middle-aged and geriatric populations have a higher prevalence of obstructive sleep apnea globally. A literature-based analysis was conducted by Benjafield et al. in 16 different nations using the American Academy of Sleep Medicine (AASM) 2012 diagnostic criteria. In both men and women aged 30 to 69 , there were roughly 936 million who had mild to severe OSA [23]. The analysis also found that nearly half of that, 425 million people, had either moderate or severe OSA [23]. The condition is still disproportionately undertreated and underdiagnosed despite such a high proportion of the population suffering from it. With a prevalence of one billion, estimates from one study show that $82 \%$ of men and $93 \%$ of women in the United States have obstructive sleep apnea but are undiagnosed [24,25]. The lack of focus on identifying and treating this condition is further emphasized by the strain it adds to the healthcare system. The estimated financial impact that undiagnosed OSA had on the United States in 2015 was $\$ 149.5$ billion. Furthermore, $\$ 30$ billion of that $\$ 149.5$ billion is thought to be due to the increased risk of resulting cardiovascular and metabolic conditions and $\$ 86.9$ billion from decreased productivity of individuals suffering from OSA. Notably, it was projected to have required less than one tenth of that total cost, $\$ 12.4$ billion dollars, to diagnose and treat OSA that year [26,27]. 


\section{Risk Factors}

Risk factors that can cause OSA include obesity, gender, age, and genetic syndromes [25]. Screening patients for these risk factors and understanding the etiology of OSA is essential for beginning treatment to prevent economic burden and health risks.

\subsection{Obesity}

Obesity is a hallmark risk factor for the manifestation and disease progression of OSA [28]. Adipose is deposited around the circumference of the neck and airway of obese patients and may lead to increased risk of pharyngeal collapse. Airway collapse causes mechanical obstruction from fat buildup and is accompanied by loss of neural control that contributes to the development of OSA [29]. A study by Peppard et al. showed that there is a direct relationship between weight gain and OSA prevalence and apnea-hypopnea index (AHI), which is calculated as the number of episodes of obstructive apnea divided by the number of hours of sleep. A 10\% increase in body weight increased the prevalence of moderate-severe OSA and AHI by six times [25,30]. Researchers at the Harvard T.H. Chaan School of Public Health speculate that one in two (48.9\%) adults in the United States will become obese and that $25 \%$ will have severe obesity by the year 2030 [31]. It is predicted that the prevalence of OSA will increase as the prevalence of obesity increases in the years to come [32].

\subsection{Gender}

Men seem to be affected by OSA more than women. The SHIP-Trend study showed than men were at a greater baseline risk of obstructive sleep apnea than women by analyzing the prevalence of OSA in 1280 participants, with the result that OSA prevalence was $59 \%$ in the men studied compared to only $33 \%$ in the females [33]. Another study performed by Whittle et al. showed via MRI that men often have more fat deposition in the neck compared to women [34]. Men's increased fat disposition causes increased neck circumferences and consequently puts them at a higher risk of airway collapse compared to women. Additionally, men's airways tend to be longer than those of women. It is hypothesized that the extended airways put men at a higher risk of pharyngeal collapse [35]. Comparing individuals with the same BMI, OSA tends to be less prevalent in women compared to men [36]. The prevalence difference observed with gender is thought to be due to the role of sex hormones during the fertile age, which tend to disappear after menopause, and may influence the prevalence and severity of OSA in older females [37].

\subsection{Age}

Older-aged individuals are at a higher risk of having OSA. The previously mentioned SHIP-Trend study found that aging steadily increased the prevalence of AHI in men and women beginning at the age of 50 [33]. The suspected mechanism of how age influences OSA prevalence is from decreased genioglossus reflex to negative pressure, which impairs dilator muscle's ability to compensate from pharyngeal collapse. Increases in type 1 collagen lead to delayed contractile-relaxant response in the pharyngeal constrictor muscle $[38,39]$. Because this compensatory response is decreased and the level of type 1 collagen in the pharyngeal constrictor muscle is increased, the contraction and relaxation response that is supposed to occur with each inspiration and expiration while sleeping is delayed [38,39]. The United Nations' 2019 report on World Population Ageing completed by the Department of Economic and Social Affairs estimates that the proportion of the population over the age of 65 will increase from roughly $9 \%$ in 2019 to about $16.7 \%$ by the year 2050. This increase in elderly population, in tandem with the expected increase in obesity, is expected to result in an increased prevalence of OSA [40].

\section{Signs and Symptoms}

The patient may be largely unaware that they are exhibiting signs or symptoms of obstructive sleep apnea since they occur while the patient is asleep. Ascertaining a history 
from a spouse or partner of the patient is vital to completing a workup of their condition. The patient may be aware that they snore, or perhaps that they wake up gasping for air; however, their partner will likely be more aware of the frequency and severity of these signs. Frequent complaints from the spouses or patients with OSA include drowsiness, headaches upon waking, xerostomia, sore throat, and unrestful sleep. Daytime sleepiness or fatigue despite sufficient opportunities to sleep that is unexplained by other medical problems are other symptoms that can occur in OSA. Patients with OSA frequently present with a recessed mandible, a high Mallampati score, a high BMI, and a limited pharyngeal space $[1,7,25]$. Screening for obstructive sleep apnea consists of using either the yes or no questions in the STOP-BANG questionnaire or the Berlin questionnaire [1,8,25]. STOPBANG questions include yes or no questions about the patient's symptoms of drowsiness, absence of breathing during sleep, presence of hypertension, BMI more than $35 \mathrm{~kg} / \mathrm{m}^{2}$, older than 50 years of age, neck circumference greater than forty centimeters, and male gender. If the screening produces a result indicating the presence of OSA, there is a recommendation for a sleep study utilizing polysomnography either at the patient's home or in a lab [25].

\section{Management and Treatment of OSA}

\subsection{Behavioral and Lifestyle Changes}

Weight loss is the most important goal for overweight patients with obstructive sleep apnea because there is a direct correlation between increased neck fat disposition and OSA onset and its progression. The American Academy of Sleep Medicine (AASM) recommends a target BMI of $25 \mathrm{~kg} / \mathrm{m}^{2}$ for overweight patients [41]. In 2019, a randomized controlled trial was conducted to analyze the effectiveness of an intensive weight-loss regimen and its effect on decreasing OSA severity in patients with severe OSA. They concluded that weight loss decreased OSA symptom severity and, additionally, these patients saw decreased cholesterol, biomarkers of inflammation, and blood glucose [42]. Positional therapy, where OSA patients sleep in a position other than on their back, has been found to be useful in preventing airway collapse. Sleeping in a supine position decreases inspirational volume, creates an unfavorable airway geometry, and limits functionality of muscles that dilate the airway [43]. AASM recommends the use of a pillow or backpack to prevent patients from sleeping in a supine position [41].

\subsection{Continuous Positive Airway Pressure (CPAP)}

Continuous Positive Airway Pressure (CPAP) is the first line intervention in OSA treatment. The mechanism behind this treatment is that it acts as a pneumatic splint by providing constant positive pressure into the airway through a mask interface, while still allowing for regular respirations [44]. The benefits seen from CPAP include increased quality of life, decreased daytime drowsiness, and decreased blood pressure [45-47]. AASM recommends CPAP as the first line agent in individuals with mild to moderate-severe OSA [41]. Unfortunately, as demonstrated by the Sleep Apnea Cardiovascular Endpoints (SAVE) clinical trial, CPAP improves OSA symptoms in mild and moderately severe cases but does not improve cardiovascular outcomes. Although there was significantly less daytime drowsiness and fewer instances of impaired breathing while asleep, there was not a difference in cardiovascular outcomes between the treatment and control groups consisting of 2717 participants with either moderate or severe OSA studied over 3.7 years [48].

\subsection{Mandibular Advancement Devices or MAD}

In patients who do not tolerate CPAP, another treatment option for OSA is a mandibular advancement device (MAD). These devices change the position of the lower jaw to move it forward and prevent the closing of the upper airway [49]. In both a systematic review and a meta-analysis of studies on CPAP and MAD, both CPAP and MAD decreased blood pressure. There was no significant difference between the two treatment options in blood pressure outcomes [50]. The AASM and the Academy of Dental Sleep Medicine 
(AADSM) created a joint practice guideline in 2015 that recommends that a mandibular advancement device customized to each person be used in patients with OSA instead of no therapy [51].

\subsection{Surgical Treatment}

There are two mainstay surgical options for OSA. One of the surgical treatments used is maxillomandibular advancement (MMA), which involves enlarging the airway by altering the position of the maxilla and the mandible. Another treatment called uvulopalatopharyngoplasty (UPPP) widens the airway by excising a section of the soft palate, uvula, and tonsil. The AASM recommends that patients be assessed for eligibility and contraindicated risk factors of surgical treatment before making decisions about these methods of therapy [41]. Ultimately, these treatments are reserved for those who do not respond well to CPAP or MAD. The authors of the SAMS trial analyzed how surgery affected the AHI and the Epworth Sleepiness Scale scores and compared the results to standard care. After six months, preliminary data from the trial concluded that patients with mild to moderate OSA improved with relation to apnea or hypoxia during sleep after either of the surgical methods described above [52].

\subsection{Hypoglossal Nerve Stimulation}

A hypoglossal nerve stimulator is similar to a pacemaker because it sends electrical impulses to the hypoglossal nerve during the breathing process, which stimulates the tongue to move away from the airway and prevent airway collapse [53,54]. A study, named the STAR trial, analyzed how hypoglossal nerve stimulation affected outcomes of obstructive sleep apnea. The trial recorded AHI, patients' levels of drowsiness, sleep quality, prevalence of snoring, and additional polysomnography measures. Follow-up after three years showed a decrease in AHI events from a median of 28.2 events/h to 6.2 events/h [55]. Patients should be screened to see if they are an ideal candidate for hypoglossal nerve stimulation and preferably have moderate to severe obstructive sleep apnea, a BMI of 32, and a lack of complete centric collapse at the soft palate. Assessment of the location of collapse should be done with drug-induced sleep endoscopy before consideration for hypoglossal nerve stimulation [56,57].

\section{Pharmacological Therapy for OSA}

At this time there are no known pharmacological agents that are universally used, or FDA approved, for the management of OSA. Currently, FDA approved pharmacological agents are used strictly for symptom management, not for disease management. There have been trials studying the effectiveness of serotonergic drugs such as fluoxetine, paroxetine, trazodone, and mirtazapine; however, none of these agents have proved efficacious in improving disease severity or management [58]. Pharmacotherapeutic options for OSA and central sleep apnea (CSA) are limited, therefore many patients remain untreated [59]. The role of pharmacotherapy in OSA at this current time is limited to assisting in management of OSA associated symptoms and disease.

\subsection{CNS Stimulants}

Despite the efficacy of CPAP in the management of OSA, non-adherence can range from 46-83\% [60]. However, even adherent patients can still experience residual daytime sleepiness while using CPAP [61]. Patients with daytime sleepiness due to OSA have a two-fold increased risk of occupational accidents, and driver sleepiness has been identified as one of the major causes of highway accidents and fatal crashes [62,63]. CNS stimulants such as modafinil and armodafinil can promote daytime wakefulness in this population [64] Although the exact mechanism of action is still not fully understood, modafinil is thought to improve wakefulness by inhibiting dopamine and norepinephrine reuptake $[65,66]$. Interestingly, modafinil's wake-promoting effects, unlike those of amphetamine, were not antagonized by the dopamine receptor antagonist haloperidol [67]. Therefore, modafinil 
and armodafinil have a unique profile with fewer adverse effects compared to those reported in traditional psychostimulants such as amphetamine or cocaine $[65,66]$. There are controversies regarding the impact of CNS stimulants on cognitive functions such as driving, since they can mask signs that a patient is physically in need of sleep [68]. Whereas modafinil is a mix of both the (S) and (R) enantiomers, armodafinil contains only the (R)enantiomer and is thought to display slightly more pharmacological potency and longer duration of action in terms of wakefulness compared to modafinil [66]. Solriamfetol binds to the dopamine and norepinephrine transporters with low affinity and inhibits the reuptake of dopamine and norepinephrine with low potency [69]. Modafinil, armodafinil, and solriamfetol have FDA approval for excessive sleepiness associated with OSA [67,69,70].

One concern with CNS stimulant use is the potential for abuse associated with this drug class. Like other CNS stimulants, modafinil and armodafinil both produce psychoactive and euphoric effects with noted drug diversion and misuse during the armodafinil post-marketing period $[67,70]$. Moreover, modafinil compared to methylphenidate in terms of its ability to produce psychoactive and euphoric effects and feelings whereas solriamfetol showed abuse potential similar to or lower than phentermine $[67,69,70]$. Patients with a significant history of past abuse of other CNS stimulants such as methylphenidate, amphetamine, or cocaine should be followed more closely when taking modafinil, armodafinil, or solriamfetol $[67,69,70]$.

Physical dependence is another potential limitation of CNS stimulant use. Abrupt cessation or dose reduction following chronic use of armodafinil can result in withdrawal symptoms, with the most common presentation being shaking, sweating, chills, nausea, vomiting, confusion, aggression, and atrial fibrillation [67]. In addition, abrupt withdrawal of armodafinil has caused deterioration of psychiatric symptoms such as depression [67]. Modafanil discontinuation has not been associated with specific withdrawal symptoms; however, sleepiness and fatigue are expected to return with discontinuation of use [70]. Similar to modafinil, there is no current evidence that abrupt discontinuation of solriamfetol will result in a consistent pattern of adverse events in individuals suggesting physical dependence or withdrawal [69]. Indeed, a risk/benefit discussion between physician and doctor should help determine the patient's needs before prescribing a CNS stimulant.

\subsection{Efficacy}

Modafinil has been shown to improve residual daytime sleepiness in patients on CPAP [71,72]. After CPAP withdrawals, modafinil may help reduce sleepiness [73]. Some limited data are available on modafinil's use in patients who are not using conventional treatments [74]. A trial showed that modafinil improved wakefulness in patients with mild to moderate OSA [74]. The most common side effects of modafinil were headache and nervousness [72]. Armodafinil has also been shown to help reduce excessive sleepiness in patients using CPAP $[75,76]$. The newest CNS stimulant, solriamfetol, helped increase wakefulness in patients with OSA $[77,78]$. Solriamfetol's efficacy seems to persist regardless of adherence to conventional OSA therapy [79]. Although no direct head to head trials have been done to date, a recent indirect treatment comparison meta-analysis of a 12 week duration of the stated CNS stimulants led to varying levels of improvement in excessive daytime sleepiness with similar safety risks [80]. Dosing for daytime sleepiness and special considerations are listed in Table 1. 
Table 1. CNS stimulant dosing and special considerations for daytime sleepiness.

\begin{tabular}{|c|c|c|}
\hline Drug & Dose & Special Considerations \\
\hline Armodafanil & $150 \mathrm{mg}$ to $250 \mathrm{mg}$ PO once daily [81] & $\begin{array}{c}\text { Use lowest effective dose in elderly to avoid potential toxicity } \\
\text { Take in morning to avoid sleep interference } \\
\text { Maximum daily dose is } 250 \mathrm{mg}\end{array}$ \\
\hline Modafanil & 200 mg PO once daily [70] & $\begin{array}{c}\text { Use lowest effective dose in elderly to avoid potential toxicity } \\
\text { Take in morning to avoid sleep interference } \\
\text { Maximum daily dose is } 400 \mathrm{mg}\end{array}$ \\
\hline Solriamfetol & $37.5 \mathrm{mg}$ PO once daily [82] & $\begin{array}{c}\text { Titrate by double the dose in at least 3-day intervals } \\
\text { Take in morning to avoid sleep interference } \\
\text { Avoid use in patients taking Monoamine Oxidase Inhibitors } \\
\text { (MAOIs) } \\
\text { Maximum daily dose is } 150 \mathrm{mg}\end{array}$ \\
\hline
\end{tabular}

\subsection{Leukotriene Antagonists}

For children who are experiencing labored breathing due to a sleep disorder, montelukast has been studied for its efficacy. Tonsillar and adenoid hypertrophy is a known risk factor for OSA, especially in the pediatric population [83]. The idea of how montelukast, a leukotriene antagonist, works in OSA is through reducing inflammation in the tonsils by inhibiting LT1 and LT2 receptors [84]. It is thought that montelukast influences the upper airway diameter [85]. Goldbart et al. studied the effects of montelukast on pediatric patients with OSA and found that there was a significant reduction in the respiratory disturbance index (RDI) over 16 weeks [86]. Kheirandish et al. studied the effects of combining budesonide nasal spray with montelukast in pediatrics and found that the therapy improved RDI after tonsillectomy or adenoidectomy [87]. Although preliminary studies are promising, there still is limited evidence available for the use of montelukast in pediatric patients with OSA and more research needs to be done to establish its role in therapy [86].

\subsection{Inhaled Nasal Corticosteroids}

Allergic rhinitis may exacerbate OSA by blocking the airway. It is believed that nasal corticosteroids can increase the upper airway diameter, alleviating symptoms of OSA [85]. Kiely et al. investigated the impact of nasal fluticasone on the AHI. The study had 23 participants and individuals with AHI values above 10/h were investigated deeper. These 13 individuals had a clinically significant reduction in AHI events from 30 to 23, a $27 \%$ reduction in AHI events. In the entire study population, there was a smaller statistically significant reduction from about $26 \mathrm{AHI}$ events to 23 , a reduction of only $15 \%$. Using fluticasone also helped to improve daytime wakefulness, reduce nasal congestion, and improve air's ability to move through the respiratory system [88].

\subsection{Carbonic Anhydrase Inhibitor}

Acetazolamide works by preventing the breakdown of carbonic acid, which leads to the accumulation of carbonic acid in the body and acidifies the $\mathrm{pH}$ of the blood. Due to the accumulation of carbonic acid, the kidneys secrete sodium, bicarbonate, chloride, and water in the urine. The clinical result is decreased blood pressure and metabolic acidosis $[85,89]$. Since acetazolamide increases blood $\mathrm{pCO}_{2}$, it is proposed that there is an interaction with hypoxic and hypercapnic stimulation and ventilation control through altering a process called loop gain $[89,90]$. Acetazolamide was shown to lower AHI in patients with OSA in many of the trials performed $[85,89]$. There was, however, not a clinically significant improvement in symptoms such as daytime sleepiness. Side effects were common in this population such as paresthesia and nocturia $[85,89,91]$. 


\subsection{Other Pharmacological Therapies}

Many pharmacological treatments have been studied in OSA but have varying efficacy. Gaisl et al. performed a meta-analysis on 58 clinical trials. The trials that showed statistically significant results over placebo consist of ondansetron with fluoxetine, spironolactone, spironolactone with furosemide, phentermine, zonisamide, dronabinol, liraglutide, and tramazoline [85]. Each of these trials had study populations of 40 or less except for liraglutide with 359 participants. These small study populations may be seen as limitations and the external validity of these studies questioned. Also, the clinical end points mostly studied were AHI; however, some other clinical endpoints studied were Epworth Sleepiness Scale (ESS) and maintenance of wakefulness test (MWT) [92-94]. It is important to consider what was studied: the baseline characteristics of the study population, the impact on AHI, and the side effect profile of these agents before using these agents off-label.

Many other agents such as clonidine, adalimumab, flumazenil, salmeterol, cilazapril, naloxone, pioglitazone, temazepam, flumazenil, salmeterol, cilazapril, naloxone, and pioglitazone, to name a few, were studied and showed statistically and clinically insignificant results [85]. Future studies may prove these agents to be clinically significant at a later time; however, at the time of publishing, these agents have not proven to have a place in therapy for OSA.

\section{Conclusions}

Obstructive sleep apnea has a high prevalence worldwide and is underdiagnosed and treated. There are many risk factors that contribute to OSA. This condition can increase one's risk of metabolic and cardiovascular diseases, decreases quality of life, and increase mortality. Over the next few decades, when the prevalence of obesity and the elderly increases, the amount of people with OSA is expected to rise. For this condition to be better diagnosed and treated, healthcare providers must be better familiarized with the epidemiology and pathophysiology of OSA. Only after proper screening can the strain on the healthcare system caused by OSA and resulting comorbidities be reduced by proper treatment. Pharmacological options are scarce and current FDA approved drugs are only for symptom management. While pharmacological therapies have been studied, none are universally used for the treatment of OSA. Current first line therapies for the management of OSA consist of weight loss, CPAP, MAD, and surgical interventions.

Author Contributions: Conceptualization, L.P. and G.U.; writing—original draft preparation, S.H., B.K.; J.M.; writing — review and editing, L.P.; visualization, L.P. and G.U.; supervision, L.P.; project administration, L.P.; funding acquisition, L.P. All authors have read and agreed to the published version of the manuscript.

Funding: The open access publishing fees for this article have been covered by the Texas A\&M University Open Access to Knowledge Fund (OAKFund), supported by the University Libraries.

Institutional Review Board Statement: Not applicable.

Informed Consent Statement: Not applicable.

Data Availability Statement: Not applicable.

Conflicts of Interest: The authors declare no conflict of interest.

\section{References}

1. Jordan, A.S.; McSharry, D.G.; Malhotra, A. Adult obstructive sleep apnoea. Lancet 2014, 383, 736-747. [CrossRef]

2. Bouzerda, A. Cardiovascular risk and obstructive sleep apnea. Pan Afr. Med. J. 2018, 29, 47. [CrossRef]

3. Nokes, B.; Raza, H.; Malhotra, A. Pulmonary hypertension and obstructive sleep apnea. J. Clin. Sleep Med. 2020, 16, 649. [CrossRef]

4. Khattak, H.K.; Hayat, F.; Pamboukian, S.V.; Hahn, H.S.; Schwartz, B.P.; Stein, P.K. Obstructive sleep apnea in heart failure: Review of prevalence, treatment with continuous positive airway pressure, and prognosis. Tex. Heart Inst. J. 2018, 45, 151-161. [CrossRef]

5. Otto-Yanez, M.; Torres-Castro, R.; Nieto-Pino, J.; Mayos, M. Obstructive sleep apnea-hypopnea and stroke. Medicina 2018, 78, $427-435$. 
6. Porto, F.; Sakamoto, Y.S.; Salles, C. Associação entre Apneia Obstrutiva do Sono e Infarto do Miocárdio: Uma Revisão Sistemática. Arq. Bras. Cardiol. 2017, 108, 361-369.

7. Tietjens, J.R.; Claman, D.; Kezirian, E.J.; De Marco, T.; Mirzayan, A.; Sadroonri, B.; Goldberg, A.N.; Long, C.; Gerstenfeld, E.P.; Yeghiazarians, Y. Obstructive sleep apnea in cardiovascular disease: A review of the literature and proposed multidisciplinary clinical management strategy. J. Am. Heart Assoc. 2019, 8, e010440. [CrossRef]

8. Salman, L.A.; Shulman, R.; Cohen, J.B. Obstructive sleep apnea, hypertension, and cardiovascular risk: Epidemiology, pathophysiology, and management. Curr. Cardiol. Rep. 2020, 22, 1-9. [CrossRef]

9. Narkiewicz, K.; Van De Borne, P.J.; Pesek, C.A.; Dyken, M.E.; Montano, N.; Somers, V.K. Selective potentiation of peripheral chemoreflex sensitivity in obstructive sleep apnea. Circulation 1999, 99, 1183-1189. [CrossRef]

10. Narkiewicz, K.; Van De Borne, P.J.H.; Cooley, R.L.; Dyken, M.E.; Somers, V.K. Sympathetic activity in obese subjects with and without obstructive sleep apnea. Circulation 1998, 98, 772-776. [CrossRef]

11. Jin, Z.-N.; Wei, Y.-X. Meta-analysis of effects of obstructive sleep apnea on the renin-angiotensin-aldosterone system. J. Geriatr. Cardiol. JGC 2016, 13, 333

12. Cai, A.; Wang, L.; Zhou, Y. Hypertension and obstructive sleep apnea. Hypertens. Res. 2016, 39, 391-395. [CrossRef]

13. Budhiraja, R.; Parthasarathy, S.; Quan, S.F. Endothelial dysfunction in obstructive sleep apnea. J. Clin. Sleep Med. 2007, 3, 409-415. [CrossRef]

14. Phillips, B.G.; Narkiewicz, K.; Pesek, C.A.; Haynes, W.; Dyken, M.; Somers, V.K. Effects of obstructive sleep apnea on endothelin-1 and blood pressure. J. Hypertens. 1999, 17, 61-66. [CrossRef]

15. Gjørup, P.H.; Sadauskiene, L.; Wessels, J.; Nyvad, O.; Strunge, B.; Pedersen, E.B. Abnormally increased endothelin-1 in plasma during the night in obstructive sleep apnea: Relation to blood pressure and severity of disease. Am. J. Hypertens. 2007, $20,44-52$. [CrossRef]

16. Ip, M.S.; Lam, B.; Chan, L.Y.; Zheng, L.; Tsang, K.W.; Fung, P.C.; Lam, W.K. Circulating nitric oxide is suppressed in obstructive sleep apnea and is reversed by nasal continuous positive airway pressure. Am. J. Respir. Crit. Care Med. 2000, 162, $2166-2171$. [CrossRef]

17. Testelmans, D.; Tamisier, R.; Barone-Rochette, G.; Baguet, J.P.; Roux-Lombard, P.; Pépin, J.L.; Lévy, P. Profile of circulating cytokines: Impact of OSA, obesity and acute cardiovascular events. Cytokine 2013, 62, 210-216. [CrossRef] [PubMed]

18. NaNadeem, R.; Molnar, J.; Madbouly, E.M.; Nida, M.; Aggarwal, S.; Sajid, H.; Naseem, J.; Loomba, R. Serum inflammatory markers in obstructive sleep apnea: A meta-analysis. J. Clin. Sleep Med. 2013, 9, 1003-1012. [CrossRef]

19. Kheirandish-Gozal, L.; Gozal, D. Obstructive sleep apnea and inflammation: Proof of concept based on two illustrative cytokines. Int. J. Mol. Sci. 2019, 20, 459. [CrossRef]

20. Yu, L.M.; Zhang, W.H.; Han, X.X.; Li, Y.Y.; Lu, Y.; Pan, J.; Mao, J.Q.; Zhu, L.Y.; Deng, J.J.; Huang, W.; et al. Hypoxia-induced ROS contribute to myoblast pyroptosis during obstructive sleep apnea via the NF-kB/HIF-1 $\alpha$ signaling pathway. Oxid. Med. Cell. Longev. 2019, 2019, 4596368. [CrossRef]

21. Seicean, S.; Kirchner, H.L.; Gottlieb, D.J.; Punjabi, N.M.; Resnick, H.; Sanders, M.; Budhiraja, R.; Singer, M.; Redline, S. Sleepdisordered breathing and impaired glucose metabolism in normal-weight and overweight/obese individuals: The Sleep Heart Health Study. Diabetes Care 2008, 31, 1001-1006. [CrossRef] [PubMed]

22. Nadeem, R.; Singh, M.; Nida, M.; Waheed, I.; Khan, A.; Ahmed, S.; Naseem, J.; Champeau, D. Effect of obstructive sleep apnea hypopnea syndrome on lipid profile: A meta-regression analysis. J. Clin. Sleep Med. 2014, 10, 475-489. [CrossRef] [PubMed]

23. Benjafield, A.V.; Ayas, N.T.; Eastwood, P.R.; Heinzer, R.; Ip, M.S.M.; Morrell, M.J.; Nunez, C.M.; Patel, S.R.; Penzel, T.; Pépin, J.L.; et al. Estimation of the global prevalence and burden of obstructive sleep apnoea: A literature-based analysis. Lancet Respir. Med. 2019, 7, 687-698. [CrossRef]

24. Young, T.; Evans, L.; Finn, L.; Palta, M. Estimation of the clinically diagnosed proportion of sleep apnea syndrome in middle-aged men and women. Sleep 1997, 20, 705-706. [CrossRef] [PubMed]

25. Rundo, J.V. Obstructive sleep apnea basics. Clevel. Clin. J. Med. 2019, 86 (Suppl. 1), 2-9. [CrossRef]

26. Watson, N.F. Health care savings: The economic value of diagnostic and therapeutic care for obstructive sleep apnea. J. Clin. Sleep Med. 2016, 12, 1075-1077. [CrossRef]

27. Tarasiuk, A.; Reuveni, H. The economic impact of obstructive sleep apnea. Curr. Opin. Pulm. Med. 2013, 19, 639-644. [CrossRef]

28. Hamilton, G.S.; Joosten, S.A. Obstructive sleep apnoea and obesity. Aust. Fam. Physician 2017, 46, 460-463.

29. Schwartz, A.R.; Patil, S.P.; Laffan, A.M.; Polotsky, V.; Schneider, H.; Smith, P.L. Obesity and obstructive sleep apnea: Pathogenic mechanisms and therapeutic approaches. Proc. Am. Thorac. Soc. 2008, 5, 185-192. [CrossRef] [PubMed]

30. Peppard, P.E.; Young, T.; Palta, M.; Dempsey, J.; Skatrud, J. Longitudinal study of moderate weight change and sleep-disordered breathing. JAMA 2000, 284, 3015-3021. [CrossRef] [PubMed]

31. Ward, Z.J.; Bleich, S.N.; Cradock, A.L.; Barrett, J.L.; Giles, C.M.; Flax, C.; Long, M.W.; Gortmaker, S.L. Projected US state-level prevalence of adult obesity and severe obesity. N. Engl. J. Med. 2019, 381, 2440-2450. [CrossRef]

32. Young, T.; Peppard, P.E.; Fau-Taheri, S.; Taheri, S. Excess weight and sleep-disordered breathing. J. Appl. Physiol. 2005, 99, 1592-1599. [CrossRef]

33. Fietze, I.; Laharnar, N.; Obst, A.; Ewert, R.; Felix, S.B.; Garcia, C.; Gläser, S.; Glos, M.; Schmidt, C.O.; Stubbe, B.; et al. Prevalence and association analysis of obstructive sleep apnea with gender and age differences-Results of SHIP-Trend. J. Sleep Res. 2019, 28, e12770. [CrossRef] 
34. Whittle, A.T.; Marshall, I.; Mortimore, I.L.; Wraith, P.K.; Sellar, R.J.; Douglas, N.J. Neck soft tissue and fat distribution: Comparison between normal men and women by magnetic resonance imaging. Thorax 1999, 54, 323-328. [CrossRef]

35. Malhotra, A.; Huang, Y.; Fogel, R.B.; Pillar, G.; Edwards, J.K.; Kikinis, R.; Loring, S.H.; White, D.P. The male predisposition to pharyngeal collapse: Importance of airway length. Am. J. Respir. Crit. Care Med. 2002, 166, 1388-1395. [CrossRef]

36. Redline, S.; Hans, M.; Krejcki, P. Differences in the age distribution and risk factors for sleep disordered breathing in blacks and whites. Am. J. Respir. Crit. Care Med. 1994, 149, 576.

37. Bonsignore, M.R.; Saaresranta, T.; Riha, R.L. Sex differences in obstructive sleep apnoea. Eur. Respir. Rev. 2019, 28, 154. [CrossRef]

38. Malhotra, A.; Huang, Y.; Fogel, R.; Lazic, S.; Pillar, G.; Jakab, M.; Kikinis, R.; White, D.P. Aging influences on pharyngeal anatomy and physiology: The predisposition to pharyngeal collapse. Am. J. Med. 2006, 119, 72.e9-72.e14. [CrossRef] [PubMed]

39. Andrade da Silva Dantas, D.; Mauad, T.; Silva, L.F.; Lorenzi-Filho, G.; Formigoni, G.G.; Cahali, M.B. The extracellular matrix of the lateral pharyngeal wall in obstructive sleep apnea. Sleep 2012, 35, 483-490. [CrossRef] [PubMed]

40. Department of Economic and Social Affairs. World Population Ageing 2019; UN: New York, NY, USA, 2020.

41. Adult Obstructive Sleep Apnea Task Force of the American Academy of Sleep Medicine. Clinical guideline for the evaluation, management and long-term care of obstructive sleep apnea in adults. J. Clin. Sleep Med. 2009, 5, 263-276. [CrossRef]

42. López-Padrós, C.; Salord, N.; Alves, C.; Vilarrasa, N.; Gasa, M.; Planas, R.; Montsserrat, M.; Virgili, M.N.; Rodríguez, C.; Pérez-Ramos, S.; et al. Effectiveness of an Intensive Weight-Loss Program for Severe Obstructive Sleep Apnea Syndrome (OSA) in Patients Undergoing CPAP Treatment: A Randomized Controlled Trial. J. Clin. Sleep Med. 2020, 16, 503-514. [CrossRef] [PubMed]

43. Joosten, S.A.; O'Driscoll, D.M.; Berger, P.J.; Hamilton, G.S. Supine position related obstructive sleep apnea in adults: Pathogenesis and treatment. Sleep Med. Rev. 2014, 18, 7-17. [CrossRef]

44. Pavwoski, P.; Shelgikar, A.V. Treatment options for obstructive sleep apnea. Neurol. Clin. Pract. 2017, 7, 77-85. [CrossRef] [PubMed]

45. Kushida, C.A.; Littner, M.R.; Hirshkowitz, M.; Morgenthaler, T.I.; Alessi, C.A.; Bailey, D.; Boehlecke, B.; Brown, T.M.; Coleman, J., Jr; Friedman, L.; et al. Practice parameters for the use of continuous and bilevel positive airway pressure devices to treat adult patients with sleep-related breathing disorders. Sleep 2006, 29, 375-380. [CrossRef]

46. Jenkinson, C.; Davies, R.J.; Mullins, R.; Stradling, J.R. Comparison of therapeutic and subtherapeutic nasal continuous positive airway pressure for obstructive sleep apnoea: A randomised prospective parallel trial. Lancet 1999, 353, 2100-2105. [CrossRef]

47. Floras, J.S. Obstructive sleep apnea syndrome, continuous positive airway pressure and treatment of hypertension. Eur. J. Pharmacol. 2015, 763, 28-37. [CrossRef]

48. McEvoy, R.D.; Antic, N.A.; Heeley, E.; Luo, Y.; Ou, Q.; Zhang, X.; Mediano, O.; Chen, R.; Drager, L.F.; Liu, Z.; et al. CPAP for Prevention of Cardiovascular Events in Obstructive Sleep Apnea. N. Engl. J. Med. 2016, 375, 919-931. [CrossRef]

49. Basyuni, S.; Barabas, M.; Quinnell, T. An update on mandibular advancement devices for the treatment of obstructive sleep apnoea hypopnoea syndrome. J. Thorac. Dis. 2018, 10 (Suppl. 1), S48. [CrossRef]

50. Bratton, D.J.; Gaisl, T.; Wons, A.M.; Kohler, M. CPAP vs mandibular advancement devices and blood pressure in patients with obstructive sleep apnea: A systematic review and meta-analysis. JAMA 2015, 314, 2280-2293. [CrossRef] [PubMed]

51. Ramar, K.; Dort, L.C.; Katz, S.G.; Lettieri, C.J.; Harrod, C.G.; Thomas, S.M.; Chervin, R.D. Clinical practice guideline for the treatment of obstructive sleep apnea and snoring with oral appliance therapy: An update for 2015: An American Academy of Sleep Medicine and American Academy of Dental Sleep Medicine clinical practice guideline. J. Clin. Sleep Med. 2015, 11, 773-827. [CrossRef]

52. MacKay, S.; Carney, A.S.; Catcheside, P.G.; Chai-Coetzer, C.L.; Chia, M.; Cistulli, P.A.; Hodge, J.C.; Jones, A.; Kaambwa, B.; Lewis, R.; et al. Effect of multilevel upper airway surgery vs medical management on the apnea-hypopnea index and patient-reported daytime sleepiness among patients with moderate or severe obstructive sleep apnea: The SAMS randomized clinical trial. JAMA 2020, 324, 1168-1179. [CrossRef]

53. Strollo, P.J., Jr.; Soose, R.J.; Maurer, J.T.; de Vries, N.; Cornelius, J.; Froymovich, O.; Hanson, R.D.; Padhya, T.A.; Steward, D.L.; Gillespie, M.B.; et al. Upper-airway stimulation for obstructive sleep apnea. N. Engl. J. Med. 2014, 370, 139-149. [CrossRef]

54. Wray, C.M.; Thaler, E.R. Hypoglossal nerve stimulation for obstructive sleep apnea: A review of the literature. World J. Otorhinolaryngol.-Head Neck Surg. 2016, 2, 230-233. [CrossRef]

55. Woodson, B.T.; Soose, R.J.; Gillespie, M.B.; Strohl, K.P.; Maurer, J.T.; de Vries, N.; Steward, D.L.; Baskin, J.Z.; Badr, M.S.; Lin, H.S.; et al. Three-year outcomes of cranial nerve stimulation for obstructive sleep apnea: The STAR trial. Otolaryngol.-Head Neck Surg. 2016, 154, 181-188. [CrossRef]

56. Baptista, P.M.; Costantino, A.; Moffa, A.; Rinaldi, V.; Casale, M. Hypoglossal nerve stimulation in the treatment of obstructive sleep apnea: Patient selection and new perspectives. Nat. Sci. Sleep 2020, 12, 151. [CrossRef] [PubMed]

57. Strohl, M.P.; Yamauchi, M.; Peng, Z.; Strohl, K.P. Insights since FDA approval of hypoglossal nerve stimulation for the treatment of obstructive sleep apnea. Curr. Sleep Med. Rep. 2017, 3, 133-141. [CrossRef]

58. Dempsey, J.A.; Veasey, S.C.; Morgan, B.J.; O’Donnell, C.P. Pathophysiology of sleep apnea. Physiol. Rev. 2010, 90, 47-112. [CrossRef]

59. Schmickl, C.N.; Landry, S.A.; Orr, J.E.; Chin, K.; Murase, K.; Verbraecken, J.; Javaheri, S.; Edwards, B.A.; Owens, R.L.; Malhotra, A. Acetazolamide for OSA and Central Sleep Apnea: A Comprehensive Systematic Review and Meta-Analysis. Chest 2020, 158, 2632-2645. [CrossRef] 
60. Weaver, T.E.; Grunstein, R.R. Adherence to continuous positive airway pressure therapy: The challenge to effective treatment. Proc. Am. Thorac. Soc. 2008, 5, 173-178. [CrossRef]

61. Launois, S.H.; Tamisier, R.; Lévy, P.; Pépin, J.-L. On treatment but still sleepy: Cause and management of residual sleepiness in obstructive sleep apnea. Curr. Opin. Pulm. Med. 2013, 19, 601-608. [CrossRef]

62. Garbarino, S.; Guglielmi, O.; Sanna, A.; Mancardi, G.L.; Magnavita, N. Risk of Occupational Accidents in Workers with Obstructive Sleep Apnea: Systematic Review and Meta-analysis. Sleep 2016, 39, 1211-1218. [CrossRef] [PubMed]

63. Ward, K.L.; Hillman, D.R.; James, A.; Bremner, A.P.; Simpson, L.; Cooper, M.N.; Palmer, L.J.; Fedson, A.C.; Mukherjee, S. Excessive daytime sleepiness increases the risk of motor vehicle crash in obstructive sleep apnea. J. Clin. Sleep Med. 2013, 9, $1013-1021$. [CrossRef] [PubMed]

64. Bittencourt, L.R.A.; Lucchesi, L.M.; Rueda, A.D.; Garbuio, S.A.; Palombini, L.O.; Guilleminault, C.; Tufik, S. Placebo and modafinil effect on sleepiness in obstructive sleep apnea. Prog. Neuro-Psychopharmacol. Biol. Psychiatry 2008, 32, 552-559. [CrossRef]

65. Minzenberg, M.J.; Carter, C.S. Modafinil: A review of neurochemical actions and effects on cognition. Neuropsychopharmacology 2008, 33, 1477-1502. [CrossRef]

66. Murillo-Rodríguez, E.; Barciela Veras, A.; Barbosa Rocha, N.; Budde, H.; Machado, S. An overview of the clinical uses, pharmacology, and safety of modafinil. ACS Chem. Neurosci. 2018, 9, 151-158. [CrossRef] [PubMed]

67. Guide, M. NUVIGIL (Armodafinil) Tablets; Teva Pharmaceuticals, Inc.: North Wales, PA, USA, 2018.

68. Kay, G.G.; Feldman, N. Effects of armodafinil on simulated driving and self-report measures in obstructive sleep apnea patients prior to treatment with continuous positive airway pressure. J. Clin. Sleep Med. 2013, 9, 445-454. [CrossRef] [PubMed]

69. Sunosi s. [Package Insert]; Jazz Pharmaceuticals, Inc.: Palo Alto, CA, USA, 2019.

70. Provigil m. [Package Insert]; Cephalon Inc.: Frazer, PA, USA, 2010.

71. Black, J.E.; Hirshkowitz, M. Modafinil for treatment of residual excessive sleepiness in nasal continuous positive airway pressuretreated obstructive sleep apnea/hypopnea syndrome. Sleep 2005, 28, 464-471. [CrossRef] [PubMed]

72. Pack, A.I.; Black, J.E.; Schwartz, J.R.L.; Matheson, J.K. Modafinil as adjunct therapy for daytime sleepiness in obstructive sleep apnea. Am. J. Respir. Crit. Care Med. 2001, 164, 1675-1681. [CrossRef]

73. Williams, S.C.; Marshall, N.S.; Kennerson, M.; Rogers, N.L.; Liu, P.Y.; Grunstein, R.R. Modafinil effects during acute continuous positive airway pressure withdrawal: A randomized crossover double-blind placebo-controlled trial. Am. J. Respir. Crit. Care Med. 2010, 181, 825-831. [CrossRef]

74. Chapman, J.L.; Kempler, L.; Chang, C.L.; Williams, S.C.; Sivam, S.; Wong, K.K.; Yee, B.J.; Grunstein, R.R.; Marshall, N.S. Modafinil improves daytime sleepiness in patients with mild to moderate obstructive sleep apnoea not using standard treatments: A randomised placebo-controlled crossover trial. Thorax 2014, 69, 274-279. [CrossRef] [PubMed]

75. Roth, T.; White, D.; Schmidt-Nowara, W.; Wesnes, K.A.; Niebler, G.; Arora, S.; Black, J. Effects of armodafinil in the treatment of residual excessive sleepiness associated with obstructive sleep apnea/hypopnea syndrome: A 12-week, multicenter, double-blind, randomized, placebo-controlled study in nCPAP-adherent adults. Clin. Ther. 2006, 28, 689-706. [CrossRef]

76. Krystal, A.D.; Harsh, J.R.; Yang, R.; Rippon, G.A.; Lankford, D.A. A double-blind, placebo-controlled study of armodafinil for excessive sleepiness in patients with treated obstructive sleep apnea and comorbid depression. J. Clin. Psychiatry 2009, 70, 32-40. [CrossRef]

77. Schweitzer, P.; Rosenberg, R.; Zammit, G. Solriamfetol for excessive sleepiness in obstructive sleep apnea (TONES 3): A randomized controlled trial [published online ahead of print 6 December 2018]. Am. J. Respir. Crit. Care Med. 2019, 10, 1421-1431. [CrossRef] [PubMed]

78. Strollo, P.J., Jr.; Hedner, J.; Collop, N.; Lorch, D.G., Jr.; Chen, D.; Carter, L.P.; Lu, Y.; Lee, L.; Black, J.; Pépin, J.L.; et al. Solriamfetol for the treatment of excessive sleepiness in OSA: A placebo-controlled randomized withdrawal study. Chest 2019, 155, 364-374. [CrossRef] [PubMed]

79. Schweitzer, P.K.; Strohl, K.P.; Mayer, G.; Rosenberg, R.; Chandler, P.; Baladi, M.; Lee, L.; Malhotra, A. Effects of solriamfetol in a long-term trial of participants with obstructive sleep apnea who are adherent or nonadherent to airway therapy. J. Clin. Sleep Med. 2021, 17, 659-668. [CrossRef] [PubMed]

80. Ronnebaum, S.; Bron, M.; Patel, D.; Menno, D.; Bujanover, S.; Kratochvil, D.; Lucas, E.; Stepnowsky, C. Indirect treatment comparison of solriamfetol, modafinil, and armodafinil for excessive daytime sleepiness in obstructive sleep apnea: Comparison of wake-promoting agents in OSA. J. Clin. Sleep Med. 2021. [CrossRef]

81. Nuvigil a. [Package Insert]; Cephalon Inc.: Frazer, PA, USA, 2010.

82. Sunosi. Sunosi ${ }^{\mathrm{TM}}$ (solriamfetol) Tablets Prescribing Information; Jazz Pharmaceuticals, Inc.: Palo Alto, CA, USA, 2019.

83. Schellenberg, J.B.; Maislin, G.; Schwab, R.J. Physical findings and the risk for obstructive sleep apnea: The importance of oropharyngeal structures. Am. J. Respir. Crit. Care Med. 2000, 162, 740-748. [CrossRef]

84. Lin, C.M.; Huang, Y.S.; Guilleminault, C. Pharmacotherapy of obstructive sleep apnea. Expert Opin. Pharmacother. 2012, 13, 841-857. [CrossRef]

85. Gaisl, T.; Haile, S.R.; Thiel, S.; Osswald, M.; Kohler, M. Efficacy of pharmacotherapy for OSA in adults: A systematic review and network meta-analysis. Sleep Med. Rev. 2019, 46, 74-86. [CrossRef] [PubMed]

86. Goldbart, A.D.; Goldman, J.L.; Veling, M.C.; Gozal, D. Leukotriene modifier therapy for mild sleep-disordered breathing in children. Am. J. Respir. Crit. Care Med. 2005, 172, 364-370. [CrossRef] 
87. Kheirandish, L.; Goldbart, A.D.; Gozal, D. Intranasal steroids and oral leukotriene modifier therapy in residual sleep-disordered breathing after tonsillectomy and adenoidectomy in children. Pediatrics 2006, 117, e61-e66. [CrossRef]

88. Kiely, J.; Nolan, P.; McNicholas, W. Intranasal corticosteroid therapy for obstructive sleep apnoea in patients with co-existing rhinitis. Thorax 2004, 59, 50-55.

89. Edwards, B.A.; Sands, S.A.; Eckert, D.J.; White, D.P.; Butler, J.P.; Owens, R.L.; Malhotra, A.; Wellman, A. Acetazolamide improves loop gain but not the other physiological traits causing obstructive sleep apnoea. J. Physiol. 2012, 590, 1199-1211. [CrossRef]

90. Burgess, K.R. New insights from the measurement of loop gain in obstructive sleep apnoea. J. Physiol. 2012, 590, 1781-1782. [CrossRef] [PubMed]

91. Whyte, K.F.; Gould, G.A.; Airlie, M.A.A.; Shapiro, C.M.; Douglas, N.J. Role of Protriptyline and Acetazolamide in the Sleep Apnea/Hypopnea Syndrome. Sleep 1988, 11, 463-472. [CrossRef] [PubMed]

92. Prasad, B.; Radulovacki, M.; Olopade, C.; Herdegen, J.J.; Logan, T.; Carley, D.W. Prospective Trial of Efficacy and Safety of Ondansetron and Fluoxetine in Patients with Obstructive Sleep Apnea Syndrome. Sleep 2010, 33, 982-989. [CrossRef]

93. Carley, D.W.; Prasad, B.; Reid, K.J.; Malkani, R.; Attarian, H.; Abbott, S.M.; Vern, B.; Xie, H.; Yuan, C.; Zee, P.C. Pharmacotherapy of Apnea by Cannabimimetic Enhancement, the PACE Clinical Trial: Effects of Dronabinol in Obstructive Sleep Apnea. Sleep 2017, 41. [CrossRef]

94. Yang, L.; Zhang, H.; Cai, M.; Zou, Y.; Jiang, X.; Song, L.; Liang, E.; Bian, J.; Wu, H.; Hui, R. Effect of spironolactone on patients with resistant hypertension and obstructive sleep apnea. Clin. Exp. Hypertens. 2016, 38, 464-468. [CrossRef] 